\title{
Synthesis and Characterization of Boehmites Obtained from Gibbsite in Presence of Different Environments
}

\author{
Ricardo Wilson Nastari Denigres Filho ${ }^{a}$, Gisele de Araujo Rocha ${ }^{a^{\star}}$, Célia Regina Montes,
}

\author{
Antonio Carlos Vieira-Coelho ${ }^{a^{*}}$
}

\author{
${ }^{a}$ Laboratório de Matérias-Primas Particuladas Prof. Pérsio de Souza Santos - LPSS, Departamento \\ de Engenharia Metalúrgica e de Materiais - PMT, Escola Politécnica da Universidade de São Paulo- \\ EPUSP, SP, Brazil \\ ${ }^{b}$ Núcleo de Pesquisas Geoquímicas e Geofisicas da Listosfera - NUPEGEL, Centro de Energia Nuclear \\ na Agricultura - CENA, Universidade de São Paulo - USP, Piracicaba, SP, Brazil
}

Received: January 11, 2016; Accepted: March 28, 2016

\begin{abstract}
In this study, results related to boehmite synthesis by hydrothermal processes starting from a Bayer commercial gibbsite are reported. The processes have been conducted from aqueous suspensions with initial acidic or alkaline $\mathrm{pH}$, without or with acetate ion, at $160^{\circ} \mathrm{C}$ for $72 \mathrm{~h}$ to $168 \mathrm{~h}$. The final materials were characterized by X-ray diffraction (XRD), thermal methods (DTA and TGA) and scanning electron microscopy (SEM). The influence of the synthesis conditions on the morphology of the boehmite crystals obtained from the gibbsite at different hydrothermal processes are discussed.
\end{abstract}

Keywords: Boehmite, Hydrothermal Synthesis, Characterization (XRD, Thermal methods, SEM)

\section{Introduction}

Boehmite $(\gamma-\mathrm{AlOOH})$, one of the two polymorphs of aluminum oxyhydroxide (the other one is diaspore, $\alpha-\mathrm{AlOOH}$ ), is a material useful in several commercial applications, for example, ceramics, abrasive materials, fire-retardants, adsorbents, catalysts and fillers for polymeric composites ${ }^{1}$. It can also be used as raw material for producing transition aluminas (mainly $\gamma-\mathrm{Al}_{2} \mathrm{O}_{3}$ ) with a large range of applications in catalysis and adsorption, and $\alpha-\mathrm{Al}_{2} \mathrm{O}_{3}$ for the production of ceramic materials (used in a broad range of applications, for instance mechanical parts, refractory materials and electric insulators) ${ }^{2}$.

To date, micro- and nano-boehmite crystals with different morphologies have been described ${ }^{3}$ : crystals of one dimension larger than the others (1D crystals), crystals with two comparable dimensions, both larger than the third (2D crystals), and crystals with sizes comparable in the three dimensions (3D crystals). 1D materials includes fibers, spindles, needles, rods, wiskers and tubes ${ }^{3-15}$. Platelets, leaves and all kind of lamellar materials can be labeled as $2 \mathrm{D}$ materials ${ }^{3,6,16-21}$. 3D materials comprise crystals with near cubic or spherical morphologies ${ }^{22-23}$, as well as three-dimensional assemblies of $1 \mathrm{D}$ or 2D crystals which receive several names as "urchin-like", "canteloup-like", "flower-like", "rosette-like", "hollow microspheres" and "three-quarte-sphere-like" structures ${ }^{24-32}$.

Boehmite can be prepared by a solid state thermal transformation of gibbsite ${ }^{2,33-39}$. Water in vapor form is released by heating gibbsite particles to $380 \mathrm{~K}$ to around $580 \mathrm{~K}^{34}$. If favorable conditions exist for the water vapor formed in the heating process to be retained within the

*e-mail: acvcoelh@usp.br gibbsite particles (coarse gibbsite particles; high heating rate; previous presence of water vapour in the system), boehmite is formed. In the absence of these conditions, gibbsite could transform directly into a transition alumina ( $\chi$-alumina) ${ }^{34,35,39}$. This mechanism, however, is still matter of discussion: for example, to Mercury et al. ${ }^{36}$, gibbsite decomposes thermally to boehmite regardless of gibbsite particle size ${ }^{36}$.

Boehmite can also be synthesized from liquid phase by hydrothermal/solvothermal routes $9,11,27,40-52$ or by sol-gel and precipitation techniques ${ }^{8,53-59}$. Experimental conditions such as aluminum source, nature of the precipitating agent, $\mathrm{pH}$, presence and nature of organic additives, temperature and time of thermal treatment (hydrothermal/solvothermal or thermal aging) may have a main influence in the resultant boehmite crystallite size and morphology ${ }^{60}$.

In most studies dealing with synthesis in liquid phase of micro or nano boehmites, aluminum sources are inorganic salts (the most common are nitrate and chloride) or organic compounds such as alkoxides. As mentioned in literature ${ }^{16}$, ${ }^{20,61}, \mathrm{pH}$ may significantly affect the morphology of boehmite crystals, with elongated shapes (1D morphologies) being favored in syntheses carried out in acid medium. Increasing $\mathrm{pH}$ (neutral or alkaline media) favors the formation of crystals with lamellar morphology (2D) or 3D near cubic or spherical morphologies.

There are few studies reporting the production of boehmite from hydrothermal treatment of commercial Bayer gibbsite $^{46,62}$. To the authors' knowledge, there are no reports published in the scientific literature dealing with hydrothermal transformation of a Bayer commercial gibbsite in boehmite in aqueous acidic medium. In a previous study conducted in our laboratory by Rocha ${ }^{63}$, boehmite was prepared from 
a commercial Bayer gibbsite by an hydrothermal treatment carried out at $160^{\circ} \mathrm{C}$ in distilled water and in aqueous acidic solutions (using acetic or nitric acid), with reaction times ranging between $24 \mathrm{~h}$ and $168 \mathrm{~h}$. At that temperature, full conversion of gibbsite into boehmite by hydrothermal treatment conducted in the presence of acetic acid was not observed. In the case of hydrothermal treatments in a medium containing nitric acid it was not observed by XRD the presence of residual gibbsite after $120 \mathrm{~h}$ treatment indicating that the conversion was complete. SEM images obtained in all syntheses (with both neutral and acidic media) indicated that the gibbsite undergoes a process of dissolution - the phase transition of gibbsite into boehmite under hydrothermal conditions seems to occur by a dissolution-precipitation mechanism, as suggested by Egorova et al ${ }^{62}$. Diamond-like tricky near "3D" (in both pure water and nitric acid solution media) and lamellar "2D" (in acetic acid solution medium) morphologies of boehmite crystals were obtained. In the lamellar " $2 \mathrm{D}$ " crystals, the thickness was in the nanoscale. These morphologies were distinct from that of the original gibbsite particles (which also shows a "3D" morphology).

It has been suggested in Rocha's mentioned work ${ }^{63}$ that the presence of acetate ion in the aqueous reaction medium would be essential for obtaining " $2 \mathrm{D}$ " morphology. In the literature, the only paper found indicating an effect of acetic acid as a directing morphology agent is the work of Zhan et al. ${ }^{64}$. However, what has been studied in this work was not an hydrothermal conversion of gibbsite to boehmite but an hydrothermal aging process of a commercial nano-boehmite.

This paper deepens Rocha's study, assessing how acidic $\mathrm{pH}$ and the presence of acetate ion in the reactional medium affect the characteristics of produced boehmites crystals.

\section{Materials And Methods}

\subsection{Materials}

Commercial gibbsite (Hydrogard GP - ALCOA) has the following chemical composition: $65.2 \% \mathrm{Al}_{2} \mathrm{O}_{3} ; 0.017 \% \mathrm{SiO}_{2}$; $0.013 \% \mathrm{Fe}_{2} \mathrm{O}_{3} ; 0.34 \% \mathrm{Na}_{2} \mathrm{O} ; 34.2 \%$ LOI $\left(1000^{\circ} \mathrm{C}\right)$. Gibbsite powder consists of platelet aggregates having a density of $2.42 \mathrm{~g} / \mathrm{cm}^{3}$. All the other reagents (potassium acetate and glacial acetic acid supplied by Brazilian companies; 65\% nitric acid from Sigma Aldrich) had commercial grade and were used as received.

\subsection{Methods}

All materials were produced by hydrothermal processes (autogenous pressure at $160^{\circ} \mathrm{C}$ ) differenced by the number and type of reagents added to the starting gibbsite, as listed below:

- process 1: in pure deionized water medium (molar ratio: $1 \mathrm{~mol} \mathrm{Al} \mathrm{:} 50$ mols $\mathrm{H}_{2} \mathrm{O}$ );

- process 2: in an aqueous medium in the presence of acetic acid (HAc) (molar ratios: $1 \mathrm{~mol} \mathrm{Al}: 1 \mathrm{~mol}$ HAc : 50 mols $\mathrm{H}_{2} \mathrm{O}$ );

- process 3: in an aqueous medium with addition of potassium acetate (KAc) (molar ratios: $1 \mathrm{~mol} \mathrm{Al}: 1 \mathrm{~mol}$ KAc : 50 mols $\mathrm{H}_{2} \mathrm{O}$ );
- process 4: in an aqueous medium in the presence of potassium acetate and acidified with nitric acid (molar ratios: $1 \mathrm{~mol} \mathrm{Al}: 1 \mathrm{~mol} \mathrm{KAc} \mathrm{:} 50 \mathrm{mols}_{2} \mathrm{O} ; \mathrm{pH}=2.0$, adjusted with $\mathrm{HNO}_{3}$ ).

Processes 3 and 4 were carried out to deepen the observation made in previous work done in our laboratory by Rocha ${ }^{63}$, according to which the acetate ion present in the reaction medium would be essential to obtain particle morphology with at least one nanometric dimension (morphologies "2D" or "1D").

All preparations were performed in intervals of $72 \mathrm{~h}$ or $168 \mathrm{~h}$, in $350 \mathrm{~mL}$ maximum capacity autoclaves made in steel with an inner PTFE cladding (manufactured in our laboratory). The properties of PTFE used for the construction of our equipment limited its operating temperature - we observed a deformation of the cladding above $160^{\circ} \mathrm{C}$ leading to leaks that prevented the establishment of hydrothermal conditions in the synthesis process.

Cooling after hydrothermal treatment occurred naturally to room temperature. The suspensions containing potassium acetate were centrifuged to remove the KAc from the solution prior to air drying due to hygroscopicity of KAc. This procedure was repeated three times, replacing the supernatant solution of each centrifugation by deionized water

The identification of the samples prepared in this study, as well as the initial $\mathrm{pH}$ of the original suspensions of the hydrothermal processes, are listed in Table 1.

\subsection{Characterization}

\subsubsection{X-Ray Diffraction (XRD)}

The samples were analyzed as dry powder passed through sieve \# 140 ABNT (particles $<105 \mu \mathrm{m}$ ). The equipment used was a Philips PW 1877 X-ray diffractometer (NUPEGEL-USP - Geochemistry and Geophysics of the Lithosphere Research Center), equipped with a $\mathrm{Cu}-\mathrm{K} \alpha$ source $(\lambda=1.54186 \AA)$, operated in the following conditions: $40 \mathrm{kV}$ and $40 \mathrm{~mA}$, scanning step $0.02^{\circ}(2 \theta)$, $1 \mathrm{~s}$ step accumulation time $1 \mathrm{~s}$, from $3^{\circ}(2 \theta)$ to $90^{\circ}(2 \theta)$.

Table 1 - Identification of the samples and their respective hydrothermal reaction conditions.

\begin{tabular}{|c|c|c|c|c|}
\hline \multirow[b]{2}{*}{$\begin{array}{l}\text { SAMPLE } \\
\text { ID }\end{array}$} & \multirow[b]{2}{*}{$\begin{array}{c}\text { REACTION } \\
\text { TIME (h) }\end{array}$} & \multicolumn{2}{|c|}{ MOLAR RATIOS $(*)$} & \multirow[b]{2}{*}{ Inicial pH } \\
\hline & & $\begin{array}{c}\text { (H) acetic } \\
\text { acid }\end{array}$ & $\begin{array}{c}\text { (K) K } \\
\text { acetate }\end{array}$ & \\
\hline b & 72 & 0 & 0 & \multirow{2}{*}{9.3} \\
\hline c & 168 & 0 & 0 & \\
\hline d & 72 & 1 & 0 & \multirow{2}{*}{3.1} \\
\hline $\mathbf{e}$ & 168 & 1 & 0 & \\
\hline f & 72 & 0 & 1 & \multirow{2}{*}{8.6} \\
\hline g & 168 & 0 & 1 & \\
\hline $\mathbf{h}$ & 72 & 0 & 1 & \multirow{2}{*}{$\begin{array}{c}2.0 \text { (with } \\
\mathrm{HNO}_{3} \\
\text { addition) }\end{array}$} \\
\hline i & 168 & 0 & 1 & \\
\hline $\mathbf{a}$ & \multicolumn{4}{|c|}{ Original gibbsite } \\
\hline
\end{tabular}

MOLAR RATIOS ${ }^{(*)}$ - molar ratios of the reagents in hydrothermal treatments : $1 \mathrm{~mol} \mathrm{Al}(\mathrm{OH})_{3}: \mathbf{( H )}$ mol acetic acid : (K) mol potassium acetate : $\mathbf{5 0}$ mols $\mathrm{H}_{2} \mathrm{O}$ 


\subsubsection{Thermal Analysis (Gravimetric and Differential - TGA and DTA)}

Samples prepared in the same way as the samples used for XRD were analysed in a Shimadzu DTG-60H equipment - Simultaneous TG-DTA (NUPEGEL-USP), operated in heating and cooling cycle from room temperature to $1100^{\circ} \mathrm{C}$ with heating rate of $10^{\circ} \mathrm{C} \mathrm{min}^{-1}$ and $\mathrm{N}_{2}$ atmosphere.

\subsubsection{Scanning Electron Microscopy (SEM)}

SEM images were obtained on two equipments: a JEOL model JSN $5600 \mathrm{LV}$, operating at $15 \mathrm{kV}$ and $20 \mathrm{kV}$ (NUPEGEL-USP), and a FEI model Inspect F50 operating at $5 \mathrm{kV}$ (PMT-EPUSP). In the case of images obtained on JEOL equipment, powder samples have been previously dispersed in deionized water using an ultrasonic device, dried directly over metal supports and coated with gold. For the SEM images took in the FEI equipment, dry powders were deposited on metallic sample holders covered with a double-sided carbon tape, receiving then a gold conducting coating.

\section{Results And Discussion}

\subsection{X-ray Diffraction (XRD)}

The results of XRD analyzes are presented in Figure 1. Identification of crystalline phases was made using ICDD files 33-0018 (gibbsite) and 21-1307 (boehmite).

Boehmite was present in all powders produced. A $72 \mathrm{~h}$ hydrothermal reaction at $160^{\circ} \mathrm{C}$ was insufficient for complete conversion of gibbsite to boehmite in most cases - the exception was the material produced in aqueous solution of potassium acetate (sample $\underline{f}$ ). There is no clear explanation for this exception with the available data in this moment. Literature reports that the boehmite rate formation in hydrothermal processes increase over $\mathrm{pH} 5.0$ due to the enhancement of dissolution-reprecipitation ${ }^{20}$. This could explain the complete transformation of gibbsite in boehmite observed in sample $\mathrm{f}$, as the initial $\mathrm{pH}$ of this preparation was 8.6 (see Table 1; reaction time $=72 \mathrm{~h}$, acetate ion present in the hydrothermal medium). However, if the complete transformation was due only to the alkaline $\mathrm{pH}$ of the starting suspension, the same should be observed for sample $\underline{b}$, which had an initial $\mathrm{pH}$ of 9.3 , and this did not occur: in this sample (reaction time $=72 \mathrm{~h}$; pure deionized water medium) the total transformation of gibbsite in boehmite was not observed.

A reaction time of $168 \mathrm{~h}$ at $160^{\circ} \mathrm{C}$ was sufficient for complete conversion of gibbsite to boehmite for most cases. By the XRD data, the exception was the material produced in an aqueous solution of potassium acetate acidified to $\mathrm{pH} 2.0$ with nitric acid (sample i): a small peak corresponding to (002) gibbsite reflection was observed in the diffractogram of this sample. The interpretation of this exception is not yet clear. In the literature, $\mathrm{Phambu}^{65}$ mentions that the acetate anion can adsorb on the surface of gibbsite forming a complex linking two $\mathrm{Al}$ atoms, called a "bridging complex". It is reasonable to assume that this absorption could occur in our case and could reduce the rate of formation of the boehmite by slowing the gibbsite dissolution process. Therefore, the hydrothermal reaction time of $168 \mathrm{~h}$ at $160^{\circ} \mathrm{C}$ would be insufficient to promote the full conversion of gibbsite. A similar effect of reducing boehmite formation rate caused by the presence of tartrate anion in the hydrothermal medium is mentioned
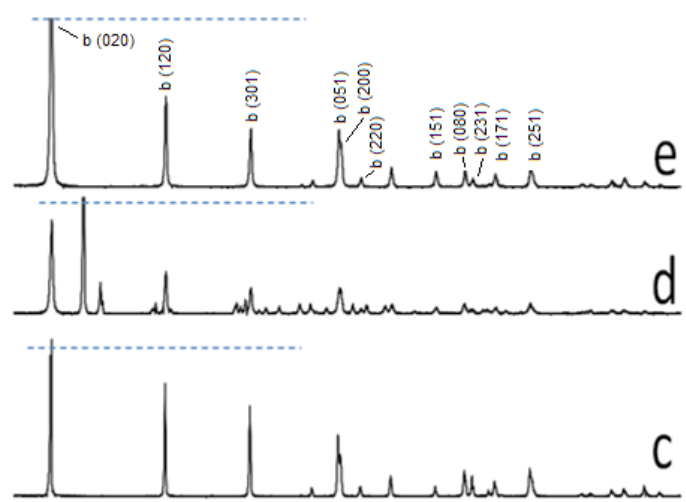

d

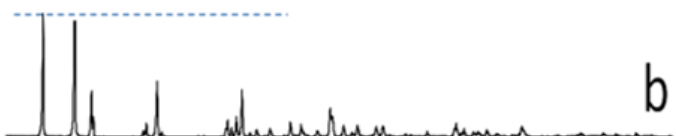

e
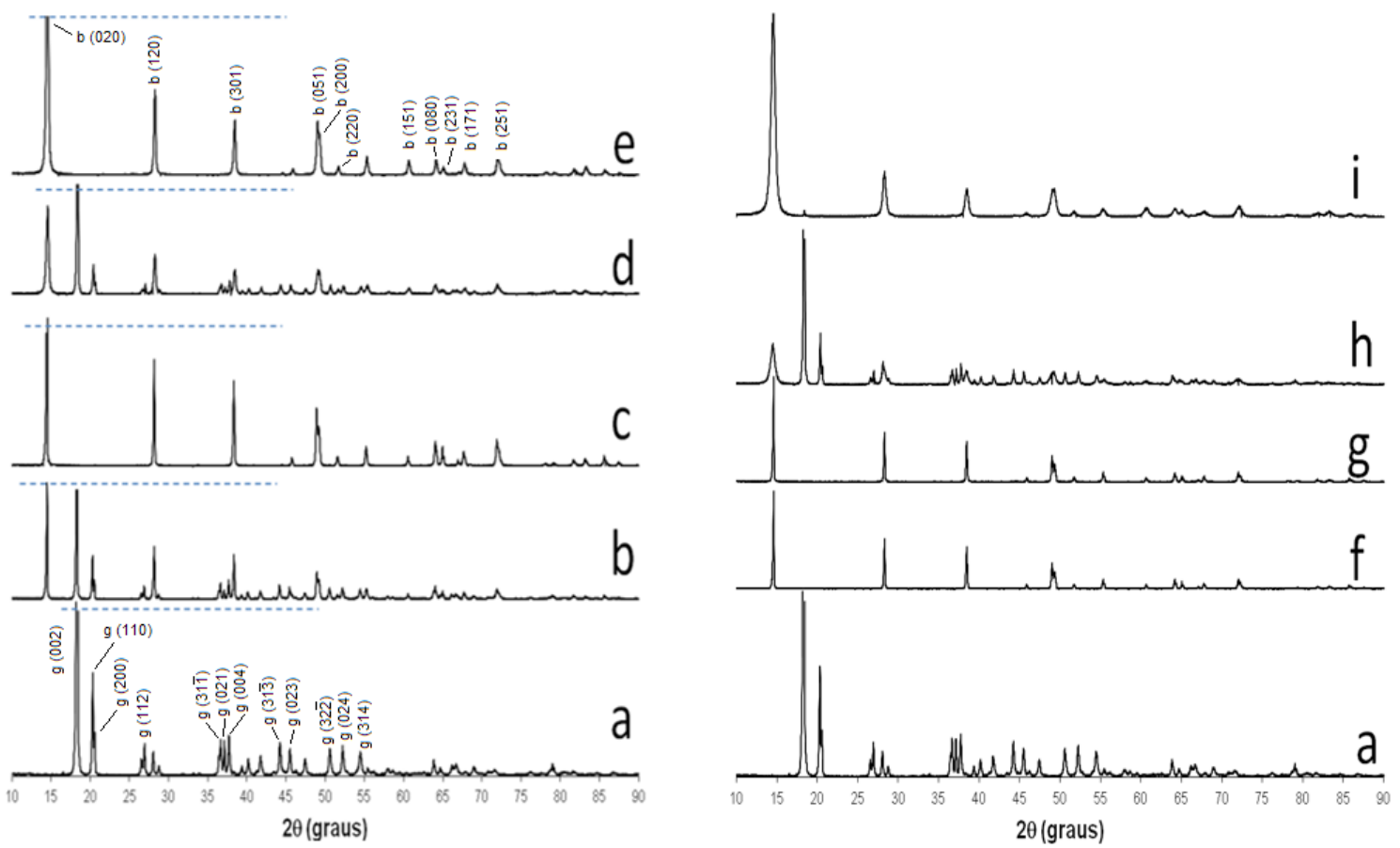

Figure 1 - XRD curves of (a) the original gibbsite and (b-i) materials prepared from hydrothermal treatments of the original gibbsite at $160^{\circ} \mathrm{C}$ at different conditions. The dotted lines indicate that the upper part of XRD curve was omitted in order to improve the observation of minor intensity peaks. Identification of the samples is given in Table 1. Identification of gibbsite and boehmite by ICDD files (gibbsite: 33-0018; boehmite: 21-1307). 
by Pardo et al. ${ }^{20}$. However, if the presence of the acetate anion in the reaction medium was the only explanation for slowing down the boehmite formation, the same behavior would be observed also in the materials produced by the processes 2 and 3. Nevertheless, in samples f-g (process 3 ) it was exactly the opposite: the complete transformation of gibbsite to boehmite has been observed after a $72 \mathrm{~h}$ hydrothermal reaction. In these samples, however, the initial $\mathrm{pH}$ was alkaline, which as mentioned above tends to accelerate the gibbsite dissolution rate.

Sharper peaks (with smaller peak width at half height) were observed in the XRD patterns of materials produced from gibbsite suspensions with initial alkaline $\mathrm{pH}$ (processes 1 and 3 , respectively $\underline{b}-\underline{c}$ and $\underline{f}$-g samples) compared to those observed in materials produced with initial acidic $\mathrm{pH}$ condition (processes 2 and 4, respectively $\underline{\mathrm{d}}-\underline{\mathrm{e}}$ and $\underline{\mathrm{h}}-\underline{\underline{i}}$ samples). This observation indicates the presence of larger crystallites in those materials as might be expected due to the enhancement of dissolution-reprecipitation in alkaline $\mathrm{pH}$.

The lack of a simple and consistent explanation for some of our experimental results indicates that the studied system is complex, requiring more detailed studies to understand the mechanism of boehmite formation by hydrothermal treatment of gibbsite in aqueous medium in the presence of acetate anion.

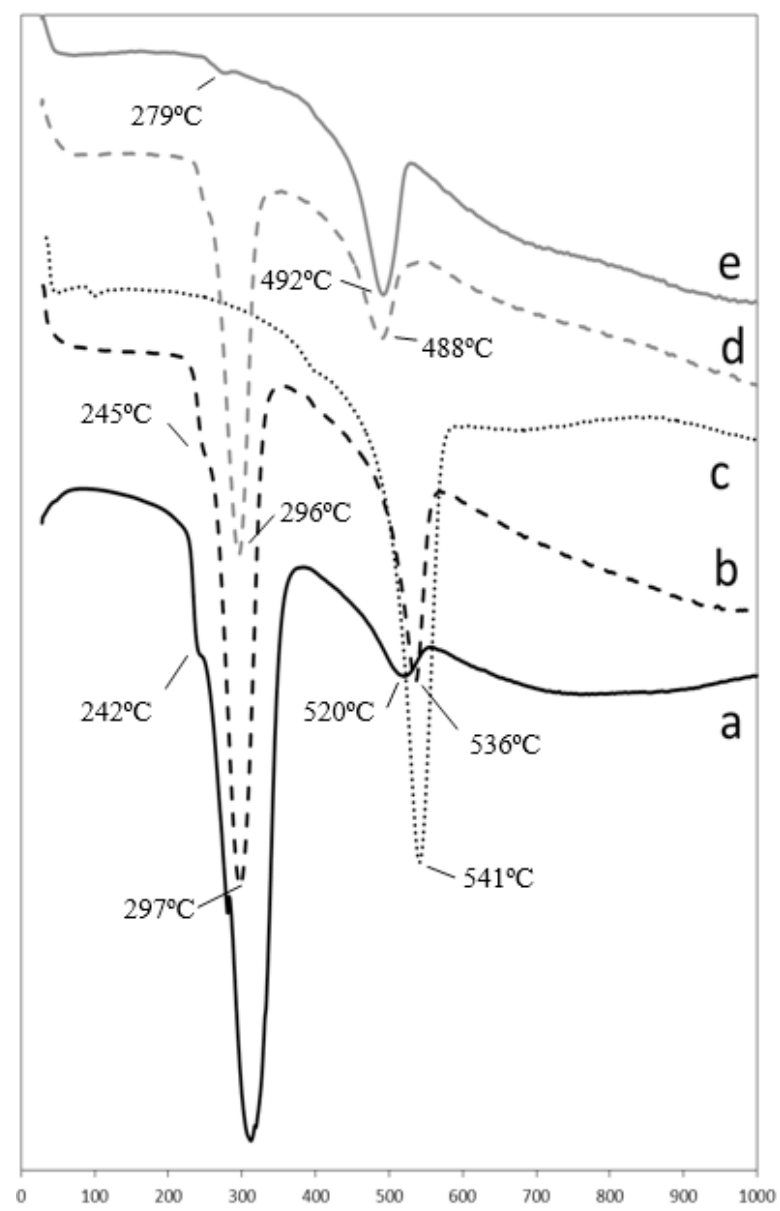

\subsection{Thermal Analysis (Gravimetric - TGA and Differential - DTA)}

DTA curves of the hydrothermal materials and of the original gibbsite are shown in Figure 2. DTA curve of the original gibbsite is consistent with what is presented in the literature ${ }^{34,66-67}$ an intense endotherm around $300^{\circ} \mathrm{C}-320^{\circ} \mathrm{C}$ and a second endotherm, less intense, above $500^{\circ} \mathrm{C}$. The first endotherm probably corresponds mainly to the thermal transformation of gibbsite to boehmite, as the gibbsite crystals are coarse and so favorable conditions to gibbsite $\rightarrow$ boehmite transformation exist, as previously mentionned. However, the conditions under which the thermal analysis was performed do not allow to exclude the possibility of formation of $\chi$-alumina ${ }^{34,35,39}$. The second endotherm corresponds to the dehydroxylation of boehmite thermally formed to transition alumina ( $\gamma$-alumina) ${ }^{34,67}$.

DTA results corresponding to different materials prepared are consistent with XRD results. In most materials produced with a reaction time of $72 \mathrm{~h}$ (samples $\underline{\mathrm{b}}, \underline{\mathrm{d}}$ and $\underline{\mathrm{h}}$ ) the conversion of gibbsite to boehmite was not complete, as evidenced by the presence of an endotherm around $300^{\circ} \mathrm{C}$ (Figure $3 \mathrm{a}-\mathrm{b}$ ). In the materials where high gibbsite to boehmite conversion was observed by XRD (samples $\underline{\mathrm{c}}, \underline{\mathrm{e}}, \underline{\mathrm{f}}, \underline{\mathrm{g}}$ and $\underline{\mathrm{i}}$ )

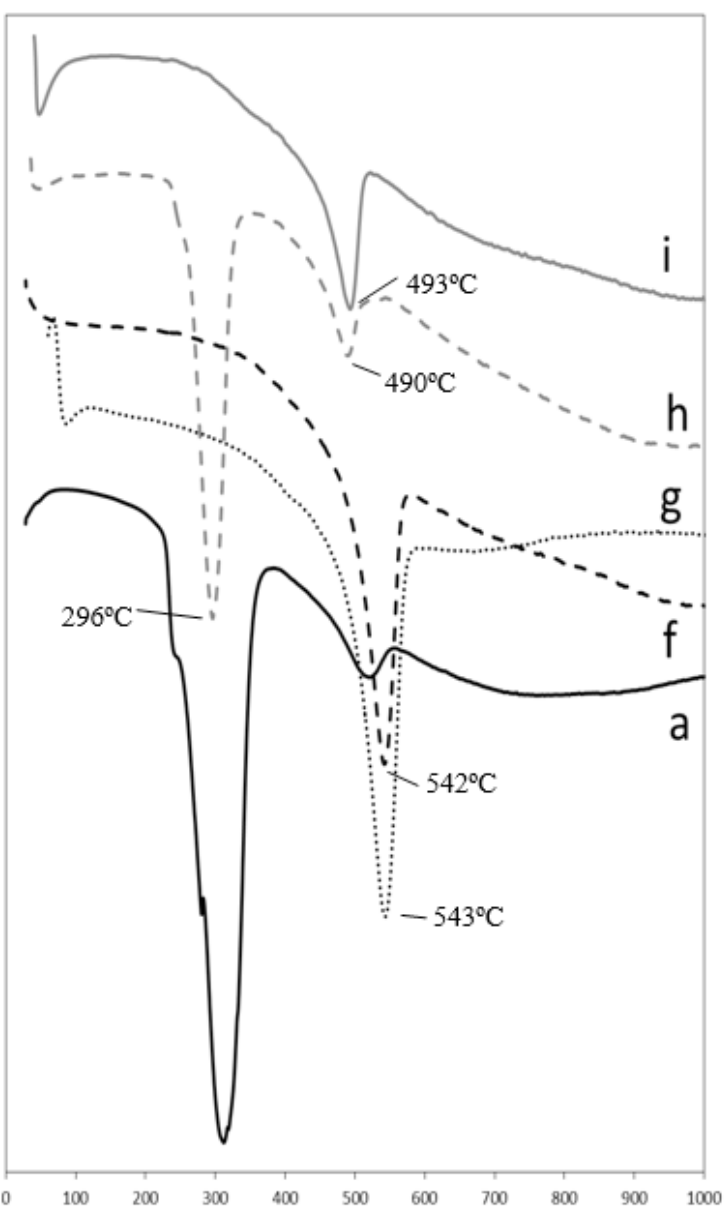

Figure 2 - DTA curves of (a) the original gibbsite and (b-i) materials prepared from hydrothermal treatments of the original gibbsite at $160^{\circ} \mathrm{C}$ at different conditions. Identification of the samples is given in Table 1. 

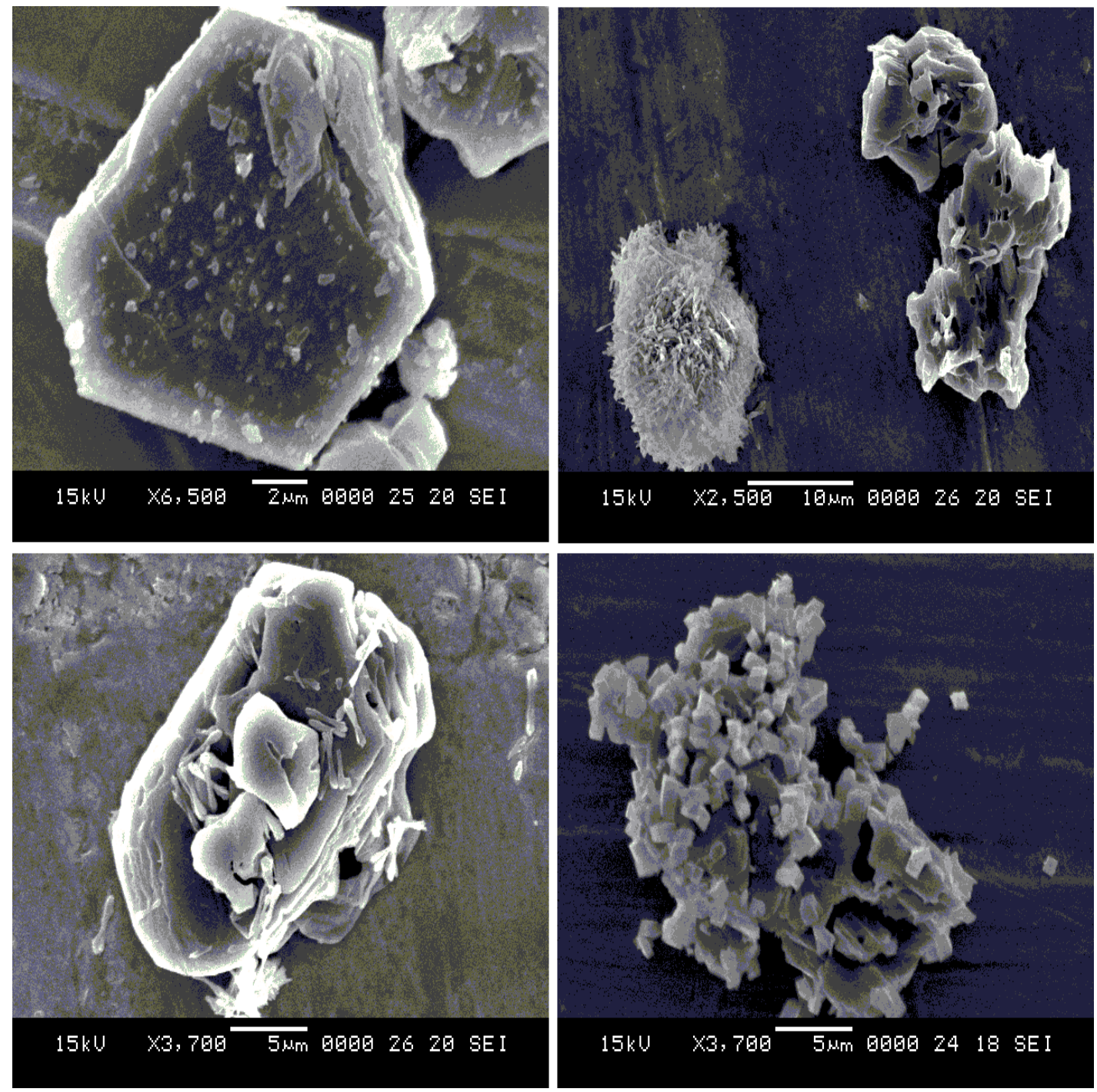

Figure 3 - SEM images of (A) the original gibbsite (from the work of Rocha 63); (B) sample d, presenting an agglomerate of boehmite particles on the left and gibbsite particles showing dissolution figures on the right; (C) sample $h$, gibbsite particle showing dissolution figures with elongated boehmite particles on its surface and around; (D) material produced under the same conditions of sample b, but with only a $48 \mathrm{~h}$ hydrothermal synthesis, showing near cubic boehmite particles on the surface of a gibbsite particle with dissolution figures (highlighted in the image; this image is presented just to show better the dissolution figures of gibbsite). Identification of the synthesis conditions of the samples is given in Table 1. (All images from JEOL equipment, NUPEGEL-USP)

almost only the second endotherm (that corresponds to the dehydroxylation of boehmite) was observed. It is interesting to note that in the case of the sample $\underline{i}$ where the presence of gibbsite is still observed by XRD it was not observed corresponding endotherm around $300^{\circ} \mathrm{C}$. In contrast, for the sample $\underline{\mathrm{e}}$, where the presence of residual gibbsite was not observed by XRD, a small endotherm was observed with maximum around $280^{\circ} \mathrm{C}$, which may indicate the presence of residual gibbsite. These two observations indicate that the experimental techniques has limitations, and it is always important for the characterization of a sample a joint analysis of the results of more than one technique.

Table 2 shows the temperatures of the two endotherms obtained from DTA curves and the weight loss percentages values of the original gibbsite and of all materials prepared.
The theoretical weight losses in thermal reactions of gibbsite and boehmite are given below:

$$
\begin{array}{lcc}
\begin{array}{l}
\text { gibbsite } \rightarrow \text { transition } \\
\text { alumina }(\chi \text {-alumina })
\end{array} & 2 \mathrm{Al}(\mathrm{OH})_{3} \rightarrow \mathrm{Al}_{2} \mathrm{O}_{3}+3 \mathrm{H}_{2} \mathrm{O} & 34.6 \% \\
\begin{array}{l}
\text { gibbsite } \rightarrow \text { boehmite } \\
\begin{array}{l}
\text { boehmite } \rightarrow \text { transition } \\
\text { alumina }(\lambda \text {-alumina })
\end{array}
\end{array} & 2 \mathrm{Al}(\mathrm{OH})_{3} \rightarrow \mathrm{AlO}(\mathrm{OH})+\mathrm{H}_{2} \mathrm{O} & 23.1 \% \\
& & 15.0 \% \\
& &
\end{array}
$$

TGA data of the original gibbsite shows a weight loss of $35.2 \%$, close to the theoretical value. The difference between the theoretical and experimental values can be attributed to moisture present in the original gibbsite.

Estimates of the relative amounts of gibbsite and boehmite, calculated using as a basis the theoretical mass 
Table 2 - Temperatures of endotherms (from DTA), weight loss percentages (from TGA) and estimates of percentages of gibbsite and boehmite (from TGA data).

\begin{tabular}{cccccccc}
\hline SAMPLE ID & $\begin{array}{c}\text { First } \\
\text { endotherm } \\
\left({ }^{\circ} \mathbf{C}\right)\end{array}$ & $\begin{array}{c}\text { Second } \\
\text { endotherm } \\
\left({ }^{\circ} \mathbf{C}\right)\end{array}$ & $\begin{array}{c}\text { \% weight loss } \\
\text { under } \mathbf{4 0 0}^{\circ} \mathbf{C}\end{array}$ & $\begin{array}{c}\text { \% weight loss } \\
\text { over 400 } \mathbf{C}\end{array}$ & $\begin{array}{c}\text { \% Total } \\
\text { weight loss }\end{array}$ & $\begin{array}{c}\text { \% gibbsite } \\
\text { (estimated) }\end{array}$ & $\begin{array}{c}\text { \% boehmite } \\
\text { (estimated) }\end{array}$ \\
\hline a & 312 & 520 & 29.6 & 5.5 & 35.2 & 100 & 0 \\
b & 297 & 536 & 17.2 & 9.2 & 26.4 & 58.2 & 41.9 \\
c & $n . o$. & 541 & 0.4 & 15.2 & 15.6 & 3.06 & 96.9 \\
d & 296 & 488 & 16.2 & 10.3 & 26.6 & 59.2 & 40.9 \\
e & 279 & 492 & 4.7 & 14.1 & 18.8 & 19.4 & 80.6 \\
f & n.o. & 543 & 0.1 & 15.7 & 15.8 & 4.08 & 95.9 \\
g & n.o. & 542 & 0.2 & 14.8 & 15.0 & 0 & 100 \\
h & 296 & 490 & 17.8 & 8.4 & 26.2 & 57.1 & 42.9 \\
i & n.o. & 493 & 4.3 & 12.3 & 16.6 & 8.16 & 91.8 \\
\hline
\end{tabular}

n.o. - endotherm not observed in DTA curve.

loss of these two phases $(34.6 \%$ for gibbsite and $15.0 \%$ for boehmite), assuming that only these two phases are present in all materials produced, are shown in Table 2.

In materials where intense reflections of gibbsite were observed by XRD (samples $\underline{b}$, e and $\underline{h}$ ), the weight loss is greater below $400^{\circ} \mathrm{C}$, which is consistent with the existence of significant amounts of residual gibbsite (not hydrothermally transformed) in these samples. Also in these same materials (samples $\underline{b}, \underline{e}$ and $\underline{h}$ ), the first endotherm (which corresponds to the thermal decomposition of gibbsite) was always be observed at temperatures around $15^{\circ} \mathrm{C}$ lower than the temperature of the same endotherm in the original gibbsite. As discussed below (in the presentation and discussion of the SEM results), the gibbsite undergoes a dissolution during the hydrothermal process, which could increase the reactivity of the residual gibbsite particles, resulting in a decrease in it thermal transformation temperature.

In two materials (samples $\underline{e}$ and $\underline{\mathrm{i}}$ ), where the existence of residual gibbsite was not clearly observed by XRD and DTA, the partial weight loss values below $400^{\circ} \mathrm{C}$ could indicate its presence.

In the remaining materials (samples $\underline{\mathrm{c}}, \underline{\mathrm{f}}$ and $\underline{\mathrm{g}}$ ) the partial weight loss values below $400^{\circ} \mathrm{C}$ are quite insignificant. The partial mass weight values above $400^{\circ} \mathrm{C}$ are very close to the theoretical value of dehydroxylation of boehmite. These results confirm the results of XRD and DTA: in these materials the transformation of gibbsite to boehmite was almost complete.

Regarding the temperature of the second endotherm (related to dehydroxylation of boehmite), the produced materials can be divided in two groups (Table 2). The first group, comprising the samples $\underline{b}, \underline{\mathrm{c}}, \underline{\mathrm{f}}$ and $\underline{\mathrm{g}}$ have the temperature of this endotherm around $540^{\circ} \mathrm{C}$, close to the temperature observed in the original gibbsite $\left(520^{\circ} \mathrm{C}\right.$, sample $\underline{\text { a }}$; decomposition of boehmite formed by thermal transformation of gibbsite). The second group samples $\underline{\mathrm{d}}, \underline{\mathrm{e}}, \underline{\mathrm{h}}$ and $\underline{\mathrm{i}}$ - show endotherm temperatures around $490^{\circ} \mathrm{C}$. As will be seen below (SEM images), this difference may be related to the morphology of boehmite crystals: in this second group of samples, boehmite crystals have elongated ("near 1D") shape. Thermal transformation of boehmite into $\gamma$-alumina could be favored by this morphology.

\subsection{Scanning Electron Microscopy (SEM)}

Figure 3 shows a typical image of the particles found in the original Bayer commercial gibbsite. This material has particles that have an hexagonal and/or pseudohexagonal shape often with some irregular contours, indicating that the material could have undergone a grinding in their fabrication process (Figure 3A).

The other three images shown in Figure 3 refers to particles observed in materials produced by hydrothermal treatments during $48 \mathrm{~h}$ and $72 \mathrm{~h}$ at different initial conditions, as follows: Figure 3B: sample $\underline{\mathrm{d}}$; Figure 3C: sample $\underline{\mathrm{h}}$; Figure 3D: same initial conditions of the sample $\underline{b}$, but with synthesis time of only $48 \mathrm{~h}$. The identification of the synthesis conditions of these samples are listed in Table 1. In these images we can see that the particles of the original gibbsite undergo a dissolution process, as evidenced by the presence of "holes" in gibbsite particles (no matter the composition of the initial solution). Gibbsite particles presenting these "dissolution figures" were observed for all the materials produced by hydrothermal synthesis for at least $48 \mathrm{~h}$ treatments.

Gibbsite particles undergoing dissolution process with neoformed boehmite crystals on its surface have been observed. Those particles coexist in the same samples with boehmite crystal agglomerates that seems to be the result of the complete transformation of other gibbsite particles (Figure 3B). In other words, in some gibbsite particles mainly dissolution occurs, while in others it may happen simultaneously dissolution of gibbsite and boehmite recrystallization on the surface of dissolving gibbsite particles. With the data we have so far we cannot explain these observations.

Boehmite is formed by a recrystallization process, regardless of their morphology ("3D" particles for sample $\underline{b}$, Figure 3D; particles with elongated shape (near "1D") for samples $\underline{\mathrm{d}}$ and $\underline{\mathrm{h}}$, Figures $3 \mathrm{~B}$ and $3 \mathrm{C}$ ). Recrystallization can occur either on the surface of gibbsite particles that are dissolving, or in the form of single crystals separated from the gibbsite particles. This was observed in all the preparations, regardless of the initial condition. So, the transformation of gibbsite into boehmite under hydrothermal conditions by a dissolution-precipitation mechanism, as suggested by Egorova ${ }^{62}$, seems to apply.

The morphology of the formed boehmite crystals is dependent on the initial conditions of hydrothermal synthesis (Figure 4). Two typical morphologies were observed according to the $\mathrm{pH}$ of the initial suspension of the hydrothermal process. Hydrothermal processes from suspensions of initial alkaline $\mathrm{pH}$ (processes 1 and 3) resulted in boehmite particles with morphologies "3D" (Figure 4A, cubes, process 1; samples $\underline{b}$ and $\underline{\mathrm{c}}$ ) or "2D" (Figure 4C, thick plates, process 3, samples $\underline{\mathrm{f}}$ 

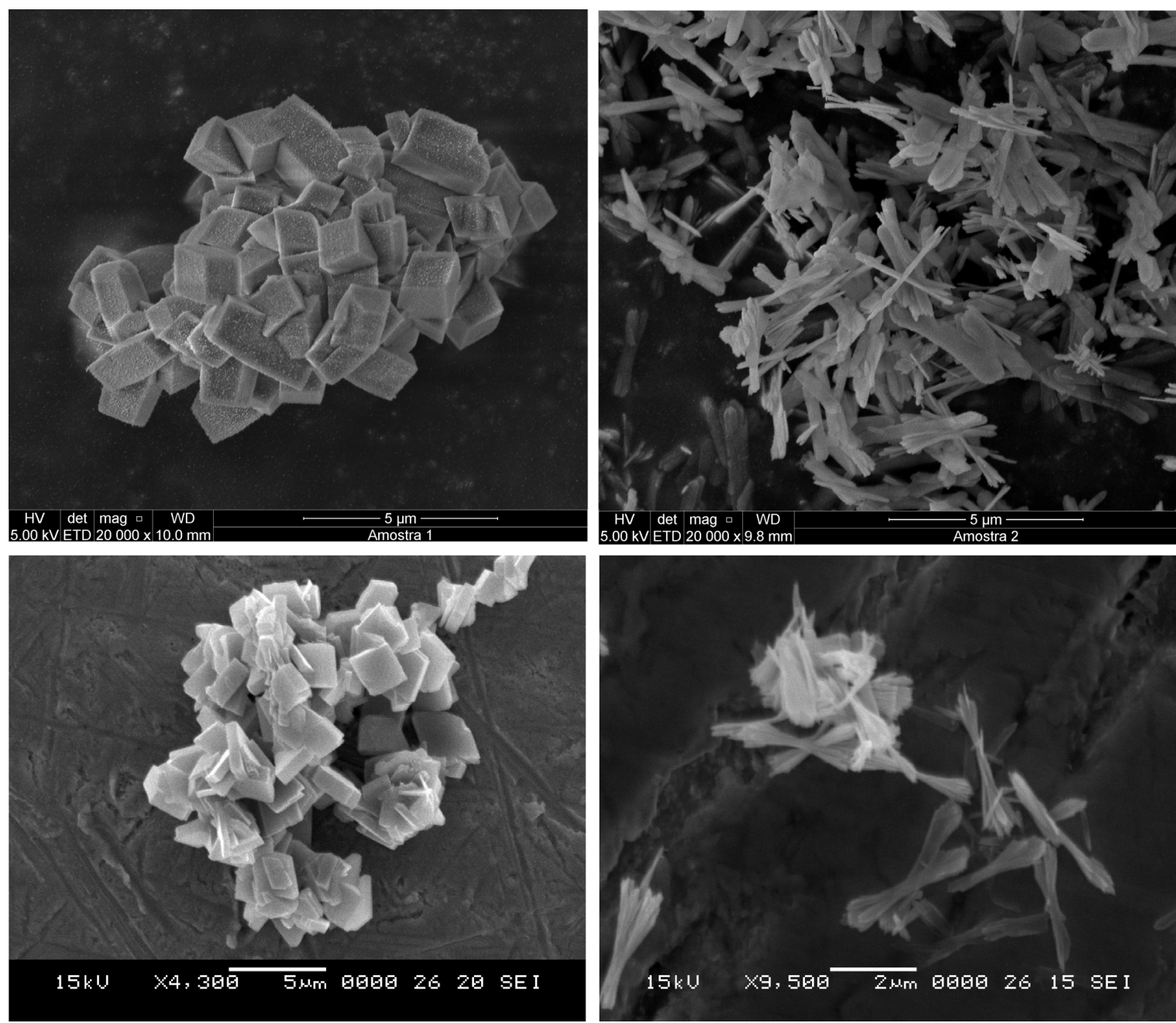

Figure 4 - SEM images of (A) sample c; (B) sample e; (C) sample f; (D) sample h. Identification of the synthesis conditions of the samples is given in Table 1. (Images A and B from FEI equipment, PMT-USP; Images C and D from JEOL equipment, NUPEGEL-USP))

and g), while processes where the initial suspension had an acidic $\mathrm{pH}$ (processes 2 and 4) resulted in elongated shape (near "1D") boehmite particles (Figure 4B, process 2, samples $\underline{\mathrm{d}}$ and $\underline{\mathrm{e}}$; Figure $4 \mathrm{D}$, process 4 , samples $\underline{\mathrm{h}}$ and $\underline{\mathrm{i}}$ ). This observation is consistent with that reported by Pardo et al. ${ }^{10,20,47}$. In these works, in which boehmite is produced from xerogels treated by hydrothermal processes, elongated particles (elongated shape attributed to the increase in the proportion of (100) and/or (001) lateral faces ${ }^{55}$ ) are obtained in processes conducted in $\mathrm{pH} 5.0$ aqueous medium, while processes carried out in aqueous medium at alkaline $\mathrm{pH}(\mathrm{pH}=10.0)$ lead to "platelet-like" particles.

The hypothesis that presence of acetate ion in the reaction medium was sufficient to produce boehmite crystals with morphologies with one or two dimensions in nanometer range (thin " $2 \mathrm{D}$ " or " $1 \mathrm{D}$ " particles) suggested by Rocha ${ }^{63}$ was not confirmed since the hydrothermal process 3 (aqueous solution of potassium acetate at its natural alkaline $\mathrm{pH}$ ) resulted in thick lamellar boehmite particles (Figure 4C). However, apparently the presence of acetate ion has led to a decrease in thickness of the boehmite crystals formed comparing to the thickness of the crystals prepared in deionized water medium, which has a "3D" morphology (Figure 4A).

The presence of acetate ion in an acidic reactional medium (processes 2 and 4 ) leads to the formation of elongated particles with nanometer scale thickness (Figures 4B and 4D). This morphology is achieved by the combined effect of acidic $\mathrm{pH}$ of the starting suspension and the presence of acetate anion in the reactional medium.

Additional studies realized recently in our laboratory show that only acidic $\mathrm{pH}$ would not be sufficient to produce elongated crystals, as can be seen in Figure 5, which shows an agglomerate of boehmite crystals produced by a hydrothermal process performed in a medium of pure deionized water acidified with nitric acid (molar ratios: $1 \mathrm{~mol} \mathrm{Al}: 50$ mols $\mathrm{H}_{2} \mathrm{O} ; \mathrm{pH}=2.0$, adjusted with $\mathrm{HNO}_{3}$ ). Boehmite crystals have the form of thin plates with nanometric thickness, not the form of diamond-like tricky "near 3D" crystals as observed in the previous work of Rocha ${ }^{63}$. To date we have no adequate explanation to this discrepancy. 


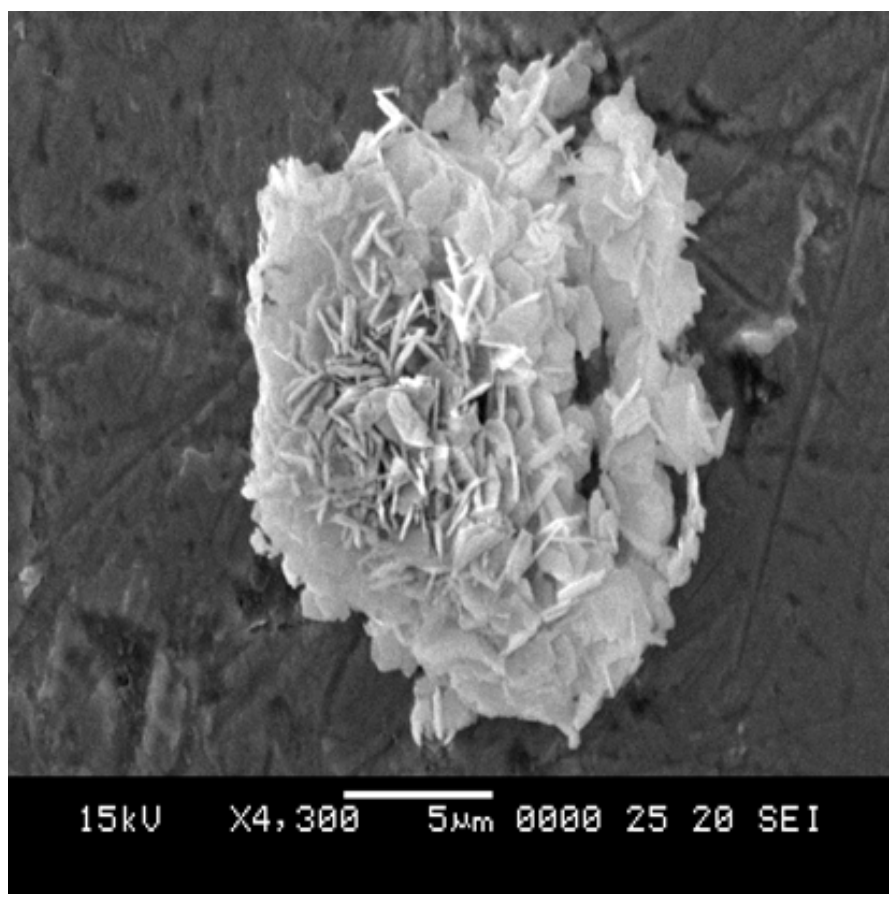

Figure 5 - SEM image of boehmite "platelet-like" particles produced by an hydrothermal process performed in pure deionized water medium acidified with nitric acid (molar ratios: 1 mol Al: 50 mol H2O; pH 2.0 adjusted with HNO3). (Image from JEOL equipment, NUPEGEL-USP)

\section{Conclusions}

In this article a procedure to obtain boehmite crystals with different shapes by a hydrothermal process conducted at $160^{\circ} \mathrm{C}$ using a Bayer commercial gibbsite as raw material is reported. The morphology of the boehmite crystals is affected by the factors studied in this work, namely $\mathrm{pH}$ and presence of the acetate anion in the reaction medium.

\section{References}

1. Stamires D, O'Connor P, Pearson G, Jones W. Preparation of quasi-crystalline boehmite, used in ceramics, abrasive materials, fire retardants, adsorbents, catalysts and fillers, by aging quasi-crystalline boehmite precursor with additive e.g. rare earth metal. US Patent US6689333-B1. USA; 11 Aug 2000. http://www.google.ch/patents/US6689333

2. Hart LD. editor. Alumina chemicals: science and technology handbook. Westerville, OH; American Ceramic Society: 1990.

3. Santos PS, Coelho AC, Santos HS, Kiyohara PK. Hydrothermal synthesis of well-crystallized boehmite crystals of various shapes. Materials Research. 2009;12 (4):437-445. http://dx.doi. org/10.1590/S1516-14392009000400012

4. Buining PA, Pathmamanoharan C, Jansen JB, Lekkerkerker HN. Preparation of colloidal boehmite needles by hydrothermal treatment of aluminum alkoxide precursors. Journal of the American Ceramic Society. 1991;74:1303-1307.

5. Cai W, Yu J, Jaroniec M. Template-free synthesis of hierarchical spindle-like $\gamma-\mathrm{Al}_{2} \mathrm{O}_{3}$ materials and their adsorption affinity towards organic and inorganic pollutants in water. Journal of Materials Chemistry. 2010;20(22):4587. http://dx.doi. org/10.1039/b924366f
The absence of the acetate anion in the reaction medium at initial alkaline $\mathrm{pH}$ favors the formation of crystals with "near 3D" dimensions. The presence of this anion in an initial alkaline medium leads to the formation of thick plates (near "2D" crystals). The presence of acetate anion in the reaction medium with an initial acid $\mathrm{pH}$ leads to boehmite crystals with elongated shape (near "1D" dimension crystals).

6. Chen XY, Zhang ZJ, Li XL, Lee SW. Controlled hydrothermal synthesis of colloidal boehmite $(\gamma-\mathrm{AlOOH})$ nanorods and nanoflakes and their conversion into - $\mathrm{A} 12 \mathrm{O} 3$ nanocrystals. Solid State Communications. 2008;145(7-8):368-373. http:// dx.doi.org/10.1016/j.ssc.2007.11.033

7. He T, Xiang L, Zhu S. Hydrothermal preparation of boehmite nanorods by selective adsorption of sulfate. Langmuir. 2008;24(15):8284-8289. http://dx.doi.org/10.1021/la8008514

8. Kuiry SC, Megen E, Patil SD, Deshpande SA, Seal S. Solutionbased chemical synthesis of boehmite nanofibers and alumina nanorods. The Journal of Physical Chemistry B. 2005;109(9): 3868-3872. http://dx.doi.org/10.1021/jp045706k

9. LiY, Liu J, Jia Z. Fabrication of boehmite AlOOH nanofibers by a simple hydrothermal process. Materials Letters. 2006;60(29):35863590. http://dx.doi.org/10.1016/j.matlet.2006.03.083

10. Pardo P, Montoya N, Alarcón J. Tuning the size and shape of nano-boehmites by a free-additive hydrothermal method. CrystEngComm. 2015;17(10):2091-2100. http://dx.doi. org/10.1039/C4CE02094D

11. Shen SC, Ng WK, Zhong ZY, Dong YC, Chia L, Tan RB. Solid-based hydrothermal synthesis and characterization of alumina nanofibers with controllable aspect ratios. Journal of the American Ceramic Society. 2009;92(6):1311-1316. http:// dx.doi.org/10.1111/j.1551-2916.2009.03005.x 
12. Zhang J, Shi F, Lin J, Wei SY, Chen D, Gao JM, et al. Nanoparticles assembly of boehmite nanofibers without a surfactant. Materials Research Bulletin. 2008;43(7): 1709-1715. http://dx.doi. org/10.1016/j.materresbull.2007.07.022

13. Zhao Y, Frost RL. Synthesis and surface characterization of yttrium doped boehmite nanofibers. Journal of Colloid and Interface Science. 2008;326(1):289-299. http://dx.doi. org/10.1016/j.jcis.2008.07.034

14. Zhao Y, Frost RL, Martens WN. Gallium-doped boehmite nanotubes and nanoribbons. A TEM, EDX, XRD, BET, and TG study. The Journal of Physical Chemistry C. 2007;111(14):5313-5324. http://dx.doi.org/10.1021/jp067897s

15. Zhu HY, Riches JD, Barry JC. $\gamma$-alumina nanofibers prepared from aluminum hydrate with poly(ethylene oxide) surfactant. Chemistry of Materials. 2002;14(5):2086-2093. http://dx.doi. org/10.1021/cm010736a

16. Chen XY, Huh HS, Lee SW. Hydrothermal synthesis of boehmite $(\gamma$-AlOOH $)$ nanoplatelets and nanowires: $\mathrm{pH}$-controlled morphologies. Nanotechnology. 2007;18 (28): 285608. http:// dx.doi.org/10.1088/0957-4484/18/28/285608

17. Chiche D, Chanéac C, Revel R, Jolivet JP. Size and shape control of $\gamma$-AlOOH boehmite nanoparticles, a precursor of $\gamma-\mathrm{Al}_{2} \mathrm{O}_{3}$ catalyst. Studies in Surface Science and Catalysis. 2006. 162:393-400. http://dx.doi.org/10.1016/S0167-2991(06)80932-8

18. Liang H, Liu L, Yang Z, Yang Y. Facile hydrothermal synthesis of uniform 3D $\gamma$-AlOOH architectures assembled by nanosheets. Crystal Research and Technology. 2010;45(2):195-198. http:// dx.doi.org/10.1002/crat.200900514

19. Liu Y, Ma D, Han X, Bao X, Frandsen W, Wang D, Su D. Hydrothermal synthesis of microscale boehmite and gamma nanoleaves alumina. Materials Letters. 2008;62(8-9):1297-1301. http://dx.doi.org/10.1016/j.matlet.2007.08.067

20. Pardo P, Calatayud JM, Alarcón J. Improvement of boehmite nanoparticles' aqueous dispersability by controlling their size, shape and crystallinity. RSC Advances. 2014;4(89):48389-48398. http://dx.doi.org/10.1039/C4RA06322H

21. Zhang X, Honkanen M, Levänen E, Mäntylä T. Transition alumina nanoparticles and nanorods from boehmite nanoflakes. Journal of Crystal Growth. 2008;310(15):3674-3679. http:// dx.doi.org/10.1016/j.jcrysgro.2008.05.016

22. Alemi A, Hosseinpour Z, Dolatyari M, Bakhtiari A. Boehmite $(\gamma$-AlOOH) nanoparticles: Hydrothermal synthesis, characterization, $\mathrm{pH}$-controlled morphologies, optical properties, and DFT calculations. Physica Status Solidi B. 2012;249(6):1264-1270. http://dx.doi.org/10.1002/pssb.201147484

23. Hu J, Jia N, Jiang JX, Ma MG, Zhu JF, Sun RC, Li JZ. Hydrothermal preparation of boehmite-doped $\mathrm{AgCl}$ nanocubes and their characterization. Materials Letters. 2011; 65(11): 1531-1534. http://dx.doi.org/10.1016/j.matlet.2011.03.012

24. Cai W, Yu J, Gu S, Jaroniec M. Facile hydrothermal synthesis of hierarchical boehmite: sulfate-mediated transformation from nanoflakes to hollow microspheres. Crystal Growth \& Design. 2010;10(9):3977-3982. http://dx.doi.org/10.1021/cg100544w

25. Feng Y, Lu W, Zhang L, Bao X, Yue B, lv Y, Shang X. One-step synthesis of hierarchical cantaloupe-like alooh superstructures via a hydrothermal route. Crystal Growth \& Design. 2008;8(4):1426-1429. http://dx.doi.org/10.1021/ $\operatorname{cg} 7007683$

26. Huang H, Wang L, Cai Y, Zhou C, Yuan Y, Zhang X, et al. Facile fabrication of urchin-like hollow boehmite and alumina microspheres with a hierarchical structure via triton X-100 assisted hydrothermal synthesis. CrystEngComm. 2015;17(6):1318-1325. http://dx.doi.org/10.1039/C4CE02133A
27. Ji G, Li M, Li G, Gao G, Zou H, Gan S, et al. Hydrothermal synthesis of hierarchical micron flower-like $\gamma$-AlOOH and $\gamma-\mathrm{Al}_{2} \mathrm{O}_{3}$ superstructures from oil shale ash. Powder Technology. 2012; 215-216: 54-58. http://dx.doi.org/10.1016/j.powtec.2011.09.005

28. Mazloumi M, Attarchi M, Lak A, Mohajerani MS, Kajbafvala A, Zanganeh S, et al. Boehmite nanopetals self assembled to form rosette-like nanostructures. Materials Letters. 2008;62(26):4184 4186. http://dx.doi.org/10.1016/j.matlet.2008.06.025

29. Tang Z, Liang J, Li X, Li J, Guo H, Liu Y, et al. Synthesis of flower-like boehmite $(\gamma$-AlOOH) via a one-step ionic liquidassisted hydrothermal route. Journal of Solid State Chemistry. 2013;202:305-314. http://dx.doi.org/10.1016/j.jssc.2013.03.049

30. Wu X, Zhang B, Wang D, Hu Z. Morphology evolution studies of boehmite hollow microspheres synthesized under hydrothermal conditions. Materials Letters. 2012;70:128-131. http://dx.doi. org/10.1016/j.matlet.2011.11.116

31. Xu B, Wang J, Yu H, Gao H. Large-scale synthesis of hierarchical flowerlike boehmite architectures. Journal of Environmental Sciences. 2011;23: S49-S52. http://dx.doi.org/10.1016/S10010742(11)61076-0

32. Zhu Y, Hou H, Tang G, Hu Q. Synthesis of three-quarter-spherelike $\gamma$-alooh superstructures with high adsorptive capacity. European Journal of Inorganic Chemistry. 2010; 6:872-878. http://dx.doi.org/10.1002/ejic.200901036

33. Rouquerol J, Rouquerol F, Ganteaume, M. Thermal decomposition of gibbsite under low pressures i. formation of the boehmitic phase. Journal of Catalysis. 1975;36(1):99-110. http://dx.doi. org/10.1016/0021-9517(75)90014-7

34. Wefers K, Misra C. Oxides and hydroxides of aluminum. Pittsburgh: ALCOA Laboratories; 1987.

35. Bhattacharya IN, Das SC, Mukherjee PS, Paul S, Mitra PK. Thermal decomposition of precipitated fine aluminium trihydroxide. Scandinavian Journal of Metallurgy. 2004;33(4):211-219. DOI: 10.1111/j.1600-0692.2004.00686.x

36. Mercury JM, Pena P, Aza AH, Sheptyakov D, Turillas X. On the decomposition of synthetic gibbsite studied by neutron thermodiffractometry. Journal of American Ceramic Society. 2005; 89(12):3728-3733. http://dx.doi.org/ 10.1111/j.15512916.2006.01191.x

37. Baranyai VS. Kristály F, Szücs I. Influence of the short time grinding on the thermal decomposition processes of gibbsite produced by the Bayer process. Materials Science and Engineering. 2013;38(1):15-27.

38. Baranyai VZ, Kristály F, Szücs I. Influence of grain and crystallite size in the gibbsite to boehmite thermal transformation. Studia UBB Chemia. 2015;60(2): 27-44.

39. Brindley GW, Choe JO. The reaction series, gibbsite $\rightarrow$ chi alumina $\rightarrow$ kappa alumina $\rightarrow$ corundum. American Mineralogist. 1961;46(7-8):771-785.

40. Fu G, Wang J, Xu B, Gao H, Xu X, Cheng H. Influence of hydrothermal temperature on structure and microstructure of boehmite. Transactions of Nonferrous Metals Society of China. 2010;20:s221-s225.

41. Kaya C, He J, Gu X, Butler E. Nanostructured ceramic powders by hydrothermal synthesis and their applications. Microporous and Mesoporous Materials. 2002;54(1-2):37-49. http://dx.doi. org/ 10.1016/S1387-1811(02)00334-7

42. Kim T, Lian J, Ma J, Duan X, Zheng W. Morphology controllable synthesis of $\gamma$-alumina nanostructures via an ionic liquidassisted hydrothermal route. Crystal Growth \& Design. 2010; 10(7):2928-2933. http://dx.doi.org/10.1021/cg901422v

43. Mathieu Y, Lebeau B, Valtchev V. Control of the morphology and particle size of boehmite nanoparticles synthesized under 
hydrothermal conditions. Langmuir. 2007;23(18):9435-9442. http://dx.doi.org/10.1021/la700233q

44. Mishra D, Anand S, Panda RK, Das RP. Hydrothermal preparation and characterization of boehmites. Materials Letters. 2000;42(1):38-45. http://dx.doi.org/10.1016/S0167577X(99)00156-1

45. Musić S, Dragčević đ, Popović, S. Hydrothermal crystallization of boehmite from freshly precipitated aluminium hydroxide. Materials Letters. 1999;40(6):269-274. http://dx.doi.org/10.1016/ S0167-577X(99)00088-9

46. Oh CJ, Yi YK, Kim SJ, Tran T, Kim MJ. Production of microcrystalline boehmite from hydrothermal processing of Bayer plant alumina tri-hydrate. Powder Technology. 2013;235: 556-562. http://dx.doi.org/10.1016/j.powtec.2012.10.041

47. Pardo P, Serrano FJ, Vallcorba O, Calatayud JM, Amigó JM, Alarcón J. Enhanced lateral to basal surface ratio in boehmite nanoparticles achieved by hydrothermal aging. Crystal Growth \& Design. 2015;15(7):3532-3538. http://dx.doi.org/10.1021/ acs.cgd.5b00629

48. Tsuchida T. Hydrothermal synthesis of submicrometer crystals of boehmite. Journal of the European Ceramic Society. 2000;20(11):1759-1764. http://dx.doi.org/ 10.1016/S09552219(00)00052-2

49. Yanagisawa K. Preparation of single crystals under hydrothermal conditions. Journal of the Ceramic Society of Japan. 2005;113:565-572. http://dx.doi.org/10.2109/jcers113;565

50. Zhang L, Zhu YJ. Microwave-assisted solvothermal synthesis of alooh hierarchically nanostructured microspheres and their transformation to $\gamma-\mathrm{al}_{2} \mathrm{O}_{3}$ with similar morphologies. The Journal of Physical Chemistry C. 2008;112(43):16764-16768. http:// dx.doi.org/ 10.1021/jp805751t

51. Zhao Y, Frost RL, Martens WN, Zhu HY. Growth and surface properties of boehmite nanofibers and nanotubes at low temperatures using a hydrothermal synthesis route. Langmuir. 2007;23(19):9850-9859. http://dx.doi.org/10.1021/la700291d

52. Amini MM, Mirzaee M. Effect of solution chemistry on preparation of boehmite by hydrothermal assisted sol-gel processing of aluminum alkoxides. Journal of Sol-Gel Science and Technology. 2005;36(1):19-23. http://dx.doi.org/10.1007/ s10971-005-4790-7

53. Bokhimi X, Sánchez-Valente J, Pedraza F. Crystallization of sol-gel boehmite via hydrothermal annealing. Journal of Solid State Chemistry. 2002;166(1):182-190. http://dx.doi. org/ 10.1006/jssc.2002.9579

54. Bokhimi X, Morales A, Valente JS. Sulfate ions and boehmite crystallization in a sol made with aluminum tri-sec-butoxide and 2-propanol. Journal of Physical Chemistry C. 2007;111: 103-107. http://dx.doi.org/ 10.1021/jp0611673

55. Chiche D, Chanéac C, Revel R, Jolivet JP. Use of polyols as particle size and shape controllers: application to boehmite synthesis from sol-gel routes. Physical Chemistry Chemical Physics. 2011;13:6241. http://dx.doi.org/ 10.1039/C0CP02075C

56. Kim SM, Lee YJ, Jun KW, Park JY, Potdar H.S. Synthesis of thermo-stable high surface area alumina powder from sol-gel derived boehmite. Materials Chemistry and Physics. 2007; 104:56-61. http://dx.doi.org/10.1016/j.matchemphys.2007.02.044

57. Nguefack M, Popa AF, Rossignol S, Kappenstein C. Preparation of alumina through a sol-gel process. Synthesis, characterization, thermal evolution and model of intermediate boehmite. Physical Chemistry Chemical Physics. 2003;5:4279-4289. http://dx.doi. org/10.1039/B306170A.

58. Musić S, Dragčević Đ, Popović S. Formation of boehmite via precipitation from aqueous solutions. Materials Letters. 1995;24:59-64. http://dx.doi.org/10.1016/0167-577X(95)00093-3

59. Hochepied JF, Nortier P. Influence of precipitation conditions ( $\mathrm{pH}$ and temperature) on the morphology and porosity of boehmite particles. Powder Technology. 2002;128(2-3):268-275. http:// dx.doi.org/10.1016/S0032-5910(02)00178-X

60. Okada K, Nagashima T, Kameshima Y, Yasumori A, Tsukada T. Relationship between formation conditions, properties, and crystallite size of boehmite. Journal of Colloid and Interface Science. 2002;253(2):308-314. http://dx.doi.org/10.1006/ jcis. 2002.8535

61. Jolivet JP, Chanéac C, Chiche D, Cassaignon S, Durupthy O, Hernandez J. Basic concepts of the crystallization from aqueous solutions: The example of aluminum oxy(hydroxi)des and aluminosilicates. Comptes Rendus Geoscience. 2011;343(23):113-122. http://dx.doi.org/10.1016/j.crte.2010.12.006

62. Egorova SR, Mukhamed'yarova AN, Lamberov AA. Specific features of the phase transition of gibbsite into boehmite under hydrothermal treatment of floccules in an aqueous suspension. Russian Journal of Applied Chemistry. 2015;88(5):758-768. http://dx.doi.org/10.1134/S1070427215050079

63. Rocha GA. Sintese e caracterização de hidróxidos de alumínio com duas dimensões nanométricas (morfologia fibrilar) ou com uma dimensão nanométrica (morfologia de placas / lâminas) [tese]. São Paulo: Universidade de São Paulo; 2013.

64. Zhang L, Jiao X, Chen D, Jiao M. $\gamma$-AlOOH nanomaterials with regular shapes: hydrothermal fabrication and $\mathrm{Cr}_{2} \mathrm{O}_{7}{ }^{2-}$ adsorption. European Journal of Inorganic Chemistry. 2011; 5258-5264. http://dx.doi.org/10.1002/ejic.201100793

65. Phambu N. Adsorption of carboxylic acids on submicrocrystalline aluminum hydroxides in aqueouss. Part I: Qualitative study by infrared and Raman spectroscopy. Applied Spectroscopy. 2002;56(6):756-761.

66. Klopprogge JT, Ruan HD, Frost RL. Thermal decomposition of bauxite minerals: infrared emission spectroscopy of gibbsite, boehmite and diaspore. Journal of Materials Science. 2002; 37(6):1121-1129. http://dx.doi.org/10.1023/A:1014303119055

67. Todor DN. Thermal analysis of minerals. Kent: Abacus Press; 1976. 